\title{
A primate model for age related macular drusen
}

\author{
G M Hope, W W Dawson, H M Engel, R J Ulshafer, M J Kessler, M B Sherwood
}

\begin{abstract}
A closed colony of semi-free-ranging rhesus monkeys maintained in isolation since 1938 by the Caribbean Primate Research Center (CPRC) is being studied as a model for age related macular drusen. Of examined colony animals $57 \cdot 7 \%$ of the monkeys and $47 \cdot 3 \%$ of their eyes have drusen. The prevalence and severity of drusen are linearly related to increasing age and are significantly higher in specific maternal lineages (matrilines). An electrophysiological estimate indicates loss of function associated with drusen. Prevalence of drusen in CPRC females is almost twice that of males, while the prevalence among CPRC animals in general appears to be several times that of monkeys from continental US facilities. Evidence suggests that the frequency of endstage lesions is also similar to that in human populations. The CPRC matriline monkeys appear to provide the best model yet reported for human age related macular drusen.
\end{abstract}

Age related macular degeneration (AMD) is a major cause of severe vision loss in the United States and the major cause in persons over $50 .{ }^{12}$ The initial clinical manifestation of $\mathrm{AMD},{ }^{3}$ and - one of the most important, ${ }^{4}$ is drusen. These are visible ophthalmoscopically as yellow-white spots in the retinal pigment epithelium (RPE) and are seen histologically as depositions of pleomorphic material beneath the RPE..$^{3-6}$ Given the significance of drusen in AMD and failure to induce them in normal eyes, it would be valuable to identify an animal species in which drusen occur spontaneously. There have been several reports of drusen and macular lesions in aging monkeys, ${ }^{6-15}$ but the condition appears rare in animals in US facilities. We have been investigating the incidence of macular signs associated with this disease in a closed colony of freeranging rhesus macaques (Macaca mulatta) at the Caribbean Primate Research Center (CPRC) of the University of Puerto Rico. While samples from this population have been described, ${ }^{6-11}$ we report new relationships between drusen and aging, resolution loss, sex, and colony

The colony was established on Cayo Santiago, a small island off the east coast of Puerto Rico, in 1938 and no new animals have been introduced since. ${ }^{16}$ Since 1956 all monkeys have been individually identified and daily census records maintained. The social history and matriarchal lineages (matrilines) for eight to 10 generations are known for each animal. Commercial monkey diet and water are provided in addition to natural forage. Only social and behavioural observations are allowed on the island except during annual medical examinations, when limited, non-invasive, biomedical research is possible. Animals removed to reduce the colony's size are housed, with a number of non-colony animals, in large, outdoor corrals at a second facility (Sabana Seca) on the Puerto Rican mainland. The CPRC maintains over 2000 monkeys, the majority being derived from original Cayo Santiago matriarchs.

We conducted 315 eye examinations on 246 monkeys from the Cayo Santiago matrilines. Sixty-one of these were repeat examinations after one to three years, and eight were accidental duplicates (after one to two days). Examinations were conducted at Sabana Seca and on Cayo Santiago. Only data from animals with traceable Cayo Santiago lineages are included in this report.

All monkeys were anaesthetised by initial intramuscular injection of ketamine hydrochloride (12 mg/kg, Vetalar), with supplementation $(6-12 \mathrm{mg} / \mathrm{kg})$ as necessary to maintain an effective level of anaesthesia. Pupils were dilated with phenylephrine (10\%, Neo-Synephrine) and tropicamide (1\%, Mydriacil). Corneas were kept moist with artificial tears (Tears Naturale) and anaesthetised with propacaine $(0.5 \%$, Alcaine).

Eye examinations consisted of notation of abnormalities of the externae and anterior segments, intraocular pressure measurement, indirect and direct ophthalmoscopy, and, for some affected monkeys, fundus photography and, rarely, fluorescein angiography. The animals were not refracted but extreme refractive errors were noted when detected under direct ophthalmoscopy.

In the retinal examinations gross abnormalities were noted, cup/disc ratios estimated, and detectable macular drusen were counted, under direct ophthalmoscopy, up to 15 . The drusen counts were recorded either directly or in quantitative increments of five, as $0, \leq 5 \ldots \leq 15,>15$. The counts were later used to categorise each eye on a five point drusen category scale ( 0 to 4 ) based purely on the numbers of drusen, as: $0=0$ drusen, $1=\leq 5$ drusen, $2=>5$ and $\leq 10$ drusen, $3=>10$ and $\leq 15$ drusen, and $4=>15$ drusen.

Drusen counts were conducted by two or more of three examiners. Initially, the drusen count for each eye was reached by consensus but more recently was taken as the mean of independently conducted and recorded counts by each of the three examiners. Multiple correlation analysis of these data indicate that the agreement among examiners is very close $(r=0.89)$ with a standard error of estimate of less than two drusen $(1 \cdot 84)$. This correlation is statistically significant $(p<0.01)$. Analysis of variance also indicated that there were no significant differences among the examiners $(F=0.50, F \quad(0.75)=1.39$, matriarchal lineages.

\section{Material and methods}

Department of
Ophthalmology,
University of Florida,
Box J-284, JHMHC,
Gainessille, Florida
32610, USA
G M Hope
W W Dawson
R J Ulshafer
M B Sherwood
Department of
Ophthalmology,
Montefiore Medical
Center
H M Engel
Caribbean Primate
Research Center,
Medical Sciences
Campus,
University of Puerto Rico
M J Kessler
Correspondence to:
Dr G M Hope.
Accepted for publication
30 May 1991


$\mathrm{W} / 2,142 \mathrm{df}$ ). Comparisons based on drusen categories yielded kappas ${ }^{17}$ between 0.40 and 0.50 for pairs of examiners. These levels of agreement are significantly $(p<0.001)$ greater than would be expected by chance. In addition the eight animals (16 eyes) accidentally reexamined on successive days provided a useful estimate of the repeatability of the measures. Drusen categories on the initial and repeat examinations were identical for 14 of the 16 eyes ( 6 at 0,6 and 1, and 2 at 4) and differed by only one category unit $(3 v 4)$ for two eyes of one animal. The test-retest correlation coefficients were 0.98 for eyes and for animals, both statistically significant $(\mathrm{p}<0.01)$. The age and parentage of the animals were unknown to the examiners until after completion of the examinations, when these data were determined from the matriarchal lineages.

Fundus photographs and fluorescein angiograms were taken with a Kowa hand-held fundus camera which had been modified to carry a $35 \mathrm{~mm}$ camera back (Pentax MX) and autowinder (Pentax). Angiograms were taken with appropriate barrier and exciter filters at 1-second intervals for 20 seconds following fluorescein injection $(10 \mathrm{mg} / \mathrm{kg}$, Fluorescite) and after 30 seconds and 3 minutes. Extensive fundus photography was not feasible under the primitive conditions on the island where over half of these animals were examined. All ophthalmic equipment was transported daily by small boat across open water to Cayo Santiago, then by hand up the island's highest hill. Examinations were conducted in an open air shelter with no light control and with unregulated electricity from portable generators. Electricity was shared and consequently was frequently inadequate for fundus camera operation. The adequacy of the photographic records could not be verified until after the opportunity to collect data was lost. Finally, small lesions clearly visible through the direct ophthalmoscope were undetectable through the fundus camera or in photographs. Under these conditions the certainty, instant verification, and greater magnification provided by the direct ophthalmoscope proved much more suitable than fundus photography for determination of quantities of drusen.

Eight monkeys shipped to our laboratories for electrophysiological estimates of visual resolution were anaesthetised and their pupils were dilated (as above). They were maintained on $25 \%$ oxygen, $75 \%$ nitrous oxide, muscle relaxant (pancuronium bromide, Elkins-Sinn), and intravenous saline. Core temperature, electrocardiogram and end tidal $\mathrm{CO}_{2}$ were monitored. All procedures were approved by the relevant Institutional Animal Care and Use Committees. Signals in response to counterphased patterns, projected on to the macula under visual control for location and focus via a modified Zeiss fundus camera, were led to specially designed low-noise preamplifiers, then processed and stored by digital computer (Nicolet Med 80). The root mean square (RMS) amplitudes were later determined from the stored signals and provided the basic data for resolution estimates.

Primary dependent variables evaluated in this report were prevalence of drusen, indicated by
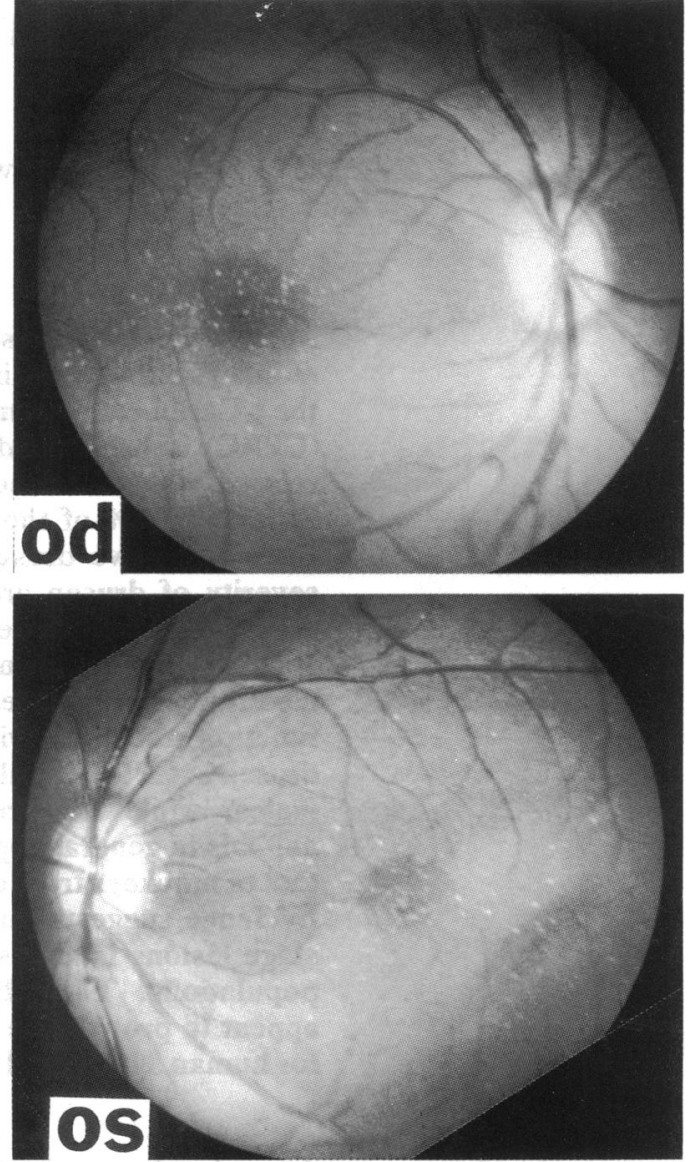

Figure 1 Fundus photographs of typical category 4 retinas Numerous drusen are obvious in both the right $(O D)$ and left (OS) fundi.

the percentages of animals and/or eyes in which drusen was present; and the relative severity, indicated by the quantitative drusen category into which each retina fell; and the visual resolution estimate described above. In most cases analyses are presented for affected monkeys and for affected eyes, consistent with similar human studies. ${ }^{18}$ Data were evaluated statistically by analysis of variance, $t$ tests, regression/correlation, and non-parametric $\chi^{2}$ analyses for contingency tables.

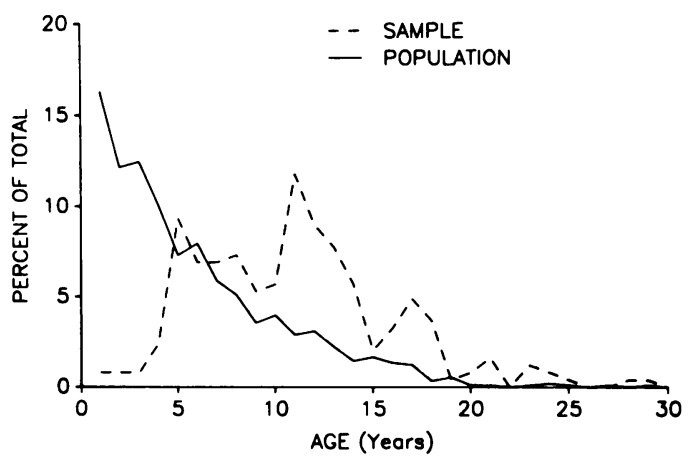

Figure 2 Age distribution of Cayo Santiago macaques. The left ordinate presents the percentages of animals at each year of age indicated on the abscissa. Distributions of the colony (solid line) and our sample (broken line) are presented. The majority of the animals in the sample distribution were over 10 years of age. 


\section{Results}

Figure 1 presents right and left eyes of monkey no. 909 , an 11 YO (at examination) female from matriline 091. Both eyes of this animal fell into drusen category 4 ( $>15$ drusen). The lesions seen here are typical of those seen in the eyes of CPRC monkeys. Note that drusen in OS appear to be larger, confluent and more foveal than in OD.

Age distributions (Fig 2) show that our sample was selective for older animals, while the colony distribution was heavily skewed by large numbers of very young monkeys. ${ }^{19}$ The majority of our sample were over 10 years of age. Ordy and Brizzee $^{20}$ have estimated that one monkey year is equal to about 3-3.5 human years. By this estimate our sample ranges up to the human equivalent of about 85-100 years of age.

A total of 490 fundi from the 246 animals from the Cayo Santiago matrilines were examined (cataracts obscured two fundi). Drusen were found in 142 of 246 animals (57.7\%) and in 232 of the 490 retinas $(47 \cdot 3 \%)$. Ages of animals whose retinas contained drusen ranged from 3 to 29 years, or $9-10$ to $85-100$ human years..$^{20}$ Percentages of affected animals and eyes increased linearly with increasing age (Fig 3 ). The correlations, $r=0.858$ and $r=0.861$, are significant $(p<0.01)$ and suggest that $74 \%$ of the variability in prevalence can be accounted for by age. Figure 4 shows a similar relationship between mean drusen category and age. The correlation coefficient $(\mathrm{r}=0.83, \mathrm{p}<0.01)$ by this measure indicates that $69 \%$ of the variability in drusen category (severity) is accounted for by age in our cross-sectional sample.

Longitudinal evidence indicates progression of the disease in 57 matriline animals re-examined after one to three years. Thirty $(52.6 \%)$ of these monkeys and 59 of the $114(51 \cdot 7 \%)$ eyes showed quantitative increases in drusen. The quantity of drusen decreased in 10 eyes of six animals over the same period. Most changes involved less than five drusen, though some monkeys went through several drusen categories. The observed proportions were significantly different $(p<0.001)$ from those expected under the assumptions of no increase or of random variability.

Of the 246 individual animals comprising the sample 114 were males and 132 were females. In Table 1 females can be seen to be significantly higher than males in every category of drusen prevalence or severity, for animals or eyes. Only differences in ages and numbers of males and females in the sample were not statistically significant. Regression analyses for prevalence among males and females against age (Fig 5) show that the slopes are very similar but the intercepts differ by about $20 \%$, indicating that increased prevalence among females was maintained across all ages.

Figure 6a-d presents distributions of percentage of affected monkeys and eyes (6a), mean drusen category (6b), mean age $(6 c)$, and number of monkeys sampled (6d) for nine matrilines. Seven additional matrilines were excluded owing to sample sizes of fewer than 10 animals. The abscissa of the first graph is organised by matrilines with decreasing prevalence, and, to aid comparison, this order is maintained in the other

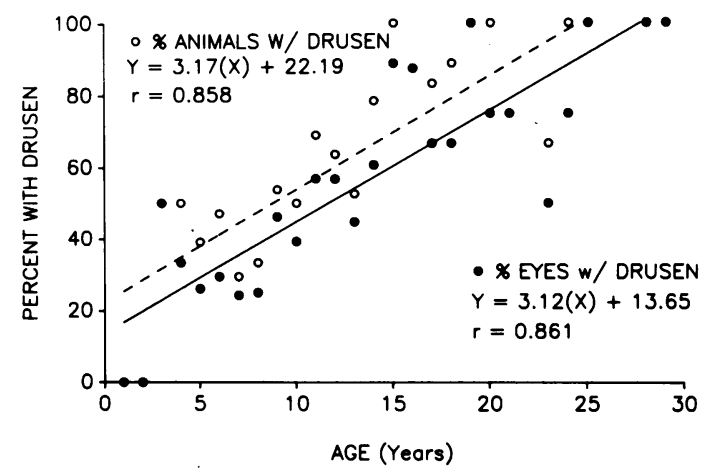

Figure 3 Relationship between age and percentage of eyes and monkeys having drusen. Abscissa is age in years, ordinate indicates percentages (monkeys and eyes) of each age which have drusen. Relationships from linear regression and correlation coefficients are provided in the upper left and lower right cormers of the graph.

graphs in this figure. Several matrilines appeared notable for relatively high percentages of eyes with drusen and higher mean drusen categories. Between $60 \%$ and $85 \%$ of the monkeys sampled from matrilines AC, 031, 076, and 091 had drusen (Fig 6a). The percentages of eyes with drusen (6a) and mean drusen categories (6b) in these matrilines were also higher than those of other matrilines. Matrilines AC, 031, 076, and 091 were significantly $(p<0.001)$ different from the others in all three measures of drusen.

These four high prevalence matrilines did not differ statistically $(\mathrm{p}<0.30)$ in mean age from the five low prevalence matrilines (Fig 6c). Extrapolation from regression equations (Figs 3 and $4)$, based on mean ages of the high $($ mean $=11 \cdot 13)$ and low $($ mean $=10.75)$ prevalence matrilines yielded expected differences of $1.25 \%$ in prevalence (animals or eyes) and 0.04 in drusen category between the two groups, as compared with differences of $25 \%$ and 0.5 , respectively, in the data. The only notable difference in sample size (Fig 6d) was the much larger sample from matriline 091. We had access to numerous 091 animals when the troop for which this was the dominant matriline was removed from the island.

Figure 7 presents RMS amplitudes of pattern evoked retinal responses to gratings in two eyes (two animals) differing in drusen size and location. The eye producing the upper curve in this figure had numerous $(>15)$ small drusen scattered throughout the macula. The eye in the

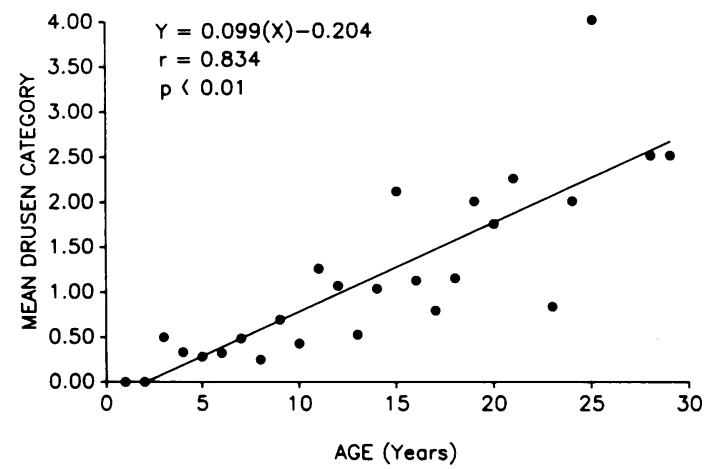

Figure 4 Relationships between age and drusen category. Abscissa is age in years, ordinate indicates mean drusen category. Relationships from linear regression and correlation coefficients are provided in the upper left corner of the graph. 


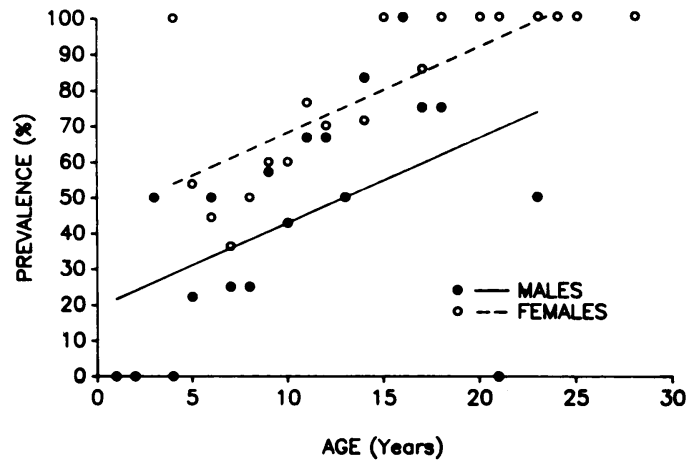

Figure 5 Relationships between age and prevalence for males and females. Abscissa is age in years, ordinate indicates prevalence in percent. Relationships from linear regression are provided in the lower right corner of the graph.

lower curve had similar quantities of drusen but one large, coalesced druse was centred directly over the fovea. The difference in pattern resolution due to these two drusen distributions is evident. A summary is presented in Table 2 which shows averaged areas (with SD and $n$ ) under similar curves for retina and cortex in response to patterns covering $15^{\circ}$ and $30^{\circ}$ for retinas having $>10$ and $\leqslant 10$ drusen. Drusen in most of these eyes were small, scattered, and non-foveal. Retinas with more than 10 druisen performed significantly worse $(p=0.044)$ in response to $30^{\circ}$ patterns, while marginal $(p=0.64)$ differences were seen with $15^{\circ}$ fields. Cortical results, however, were not different.

\section{Discussion}

In order to identify an animal model for any disease the signs in animals should mimic those
Table 1 Comparisons of drusen in retinas of male and female monkeys

\begin{tabular}{|c|c|c|c|}
\hline & Males & Females & Total \\
\hline \multicolumn{4}{|l|}{ Monkeys } \\
\hline Number & & 132 & 246 \\
\hline$\%$ Total sample & $46 \cdot 3$ & $53 \cdot 7$ & 100 \\
\hline Mean age (yrs) & 10.98 & $11 \cdot 4$ & $11 \cdot 2$ \\
\hline Number with drusen $\star \star$ & 53 & 89 & 142 \\
\hline$\%$ of same sex $\star \star$ & $46 \cdot 5$ & $67 \cdot 4$ & \\
\hline$\%$ of all with drusen $\star \star \star$ & $37 \cdot 3$ & $62 \cdot 7$ & 100 \\
\hline$\%$ total sample & $21 \cdot 5$ & $36 \cdot 2$ & $57 \cdot 7$ \\
\hline \multicolumn{4}{|l|}{ Eyes } \\
\hline Number & 226 & 264 & 490 \\
\hline$\%$ total sample & $46 \cdot 1$ & 53.9 & 100 \\
\hline Number with drusen ${ }^{\star \star \star}$ & 81 & 151 & 232 \\
\hline$\%$ of same sex ${ }^{\star \star}$ & $35 \cdot 8$ & $57 \cdot 1$ & \\
\hline$\%$ of all with drusen $\star \star \star$ & $34 \cdot 9$ & $65 \cdot 1$ & 100 \\
\hline$\%$ total sample ${ }^{\star}$ & $16 \cdot 5$ & $30 \cdot \overline{8}$ & $47 \cdot 3$ \\
\hline Mean drusen category $\star \star \star$ & 0.52 & 1.02 & 0.79 \\
\hline
\end{tabular}

${ }^{\star \star \star} \mathrm{p}<0.001 ;{ }^{\star \star} \mathrm{p}<0.01 ;{ }^{\star} \mathrm{p}<0.05$.

of humans. While there is no general agreement on which human signs and symptoms are necessary to diagnose age related macular degeneration, ${ }^{1}$ some of the more frequently used are: $(a)$ presence of drusen, the typical early lesion; $(b)$ relationship of drusen to aging; $(c)$ vision loss accompanying drusen; (d) late occurrence of exudative or dry disciform lesions.

In addition a number of secondary characteristics have been associated with AMD in humans, including consistently greater prevalence in females than males and relationships between familial (especially maternal) and individual occurrence of the disease. ${ }^{121821-23}$ The case for a model would be strengthened if all features (including secondary ones) of the human disease could be demonstrated in the animal population. Results from the CPRC rhesus macaque colony suggest that this population has all of the important, drusen related features as well as several of
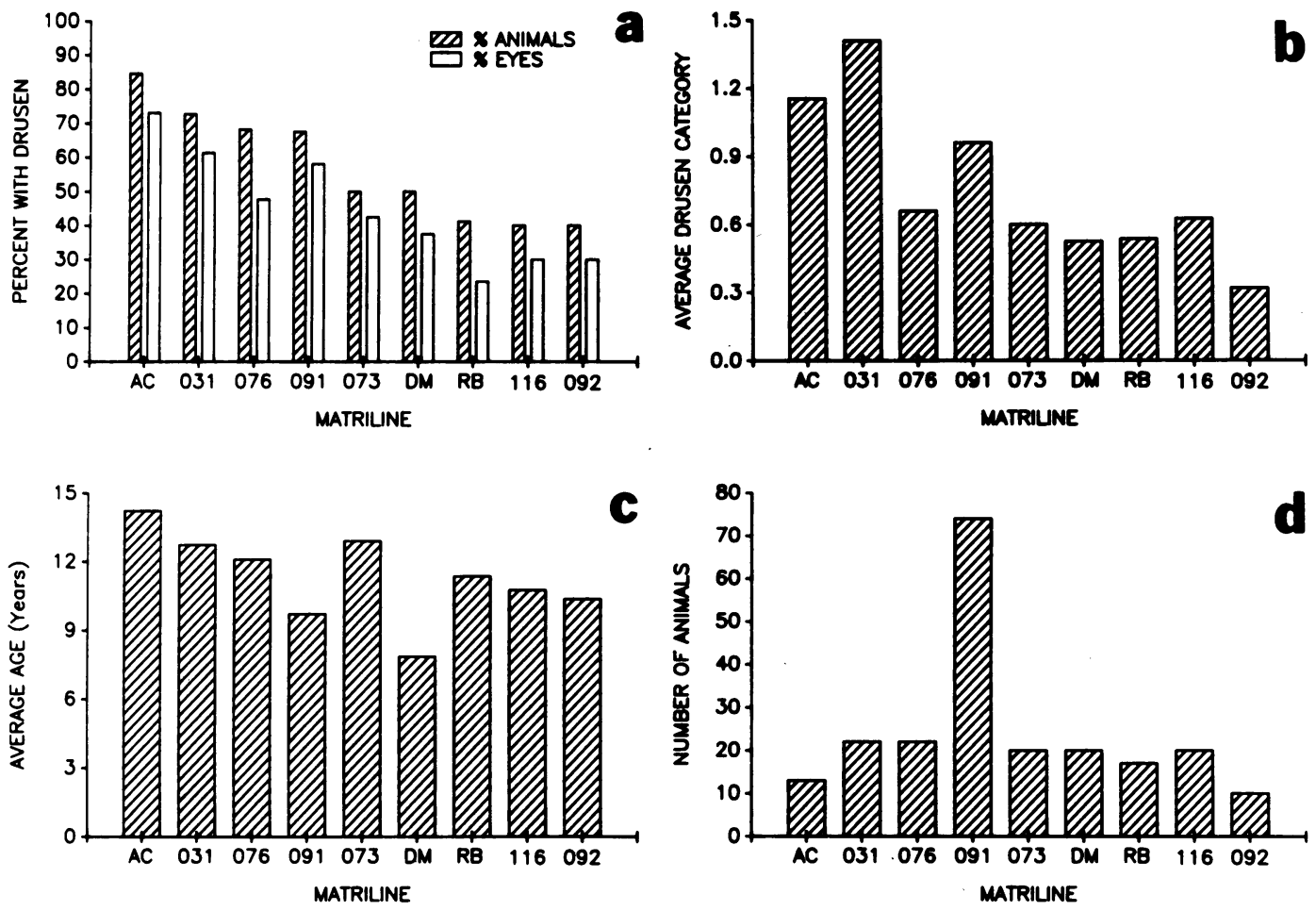

Figure 6 Variation of sample characteristics with matriline. Levels of each ordinal variable are presented versus matriarchal lineages on the abscissa. The matrilines are ordered by decreasing percentage of eyes having drusen in $6 a$ and this order is maintained in $6 b-d$. 


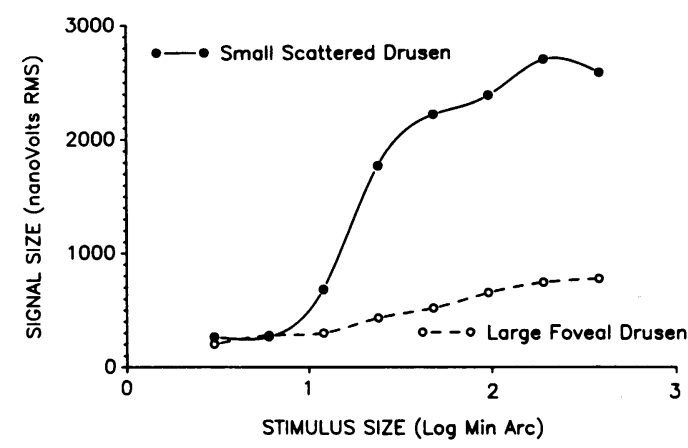

Figure 7 Relationships between resolution and drusen. Comparison of effects of small scattered drusen (solid line, filled symbols) and large foveal drusen (dashed line, open symbols). Data are root mean square amplitudes from retinas on which patterned stimuli subtending the visual angles on the abscissa are projected under visual control.

the epidemiological characteristics of the disease.

The presence of drusen in the eyes of CPRC monkeys and the histopathological similarity of drusen in monkey eyes to drusen in human eyes have been firmly established. ${ }^{6-11}$ 13-15 24 However, in monkey eyes, vacuolated or lipid filled pigmented epithelial (PE) cells can appear virtually identical to drusen. ${ }^{12} 1425$ Stafford et $a l^{14}$ noted the difficulty in distinguishing between the two, but Fine and Kwapein ${ }^{12}$ speculated that it might be possible to differentiate by the small size and solitary nature of the lipid laden PE cells. We have used the term 'drusen' to refer to the ophthalmoscopic yellowish-white figures in these monkey fundi, which is consistent with its application in clinical medicine. While a small portion of the drusen in our animals have proved - to be abnormal PE cells on microscopic examination, a demonstrated increase with age and frequent confluence argue that most are the 'true' drusen we have described at both electron and light microscopic levels. ${ }^{6}$

El-Mofty $e t a l^{10}$ found an increase in macular drusen across five increasing age groups of CPRC animals. Bellhorn $e t a^{26}$ found that macular score increased with age among the five age groups into which they divided their sample, but in grades 3 and 4 alone (dependent on drusen) the prevalence appeared to peak at 11-15 years, then decrease in both older and younger animals. Our results establish firm, linear relationships between drusen and aging. The high correlations associated with these relationships, significant intraanimal increases in drusen over one to three years, and previous observations ${ }^{10}$ firmly establish that drusen progression in CPRC animals is age related.

Relationships between pattern evoked potentials and visual acuity and dependence of cortical signals on foveal integrity have been established previously. ${ }^{27-29}$ The reduced effect of drusen on signals from smaller stimulation fields (greater foveal influence) and unaffected foveally dominated cortical responses is to be expected in these animals whose foveas were mostly intact. We have previously described a non-matriline CPRC monkey whose pattern evoked responses indicated resolution of about 220 minutes of arc in an affected eye compared with about 30 minutes in the unaffected companion. ${ }^{78} \mathrm{El}$ Mofty $e t a l^{10}$ reported reduction in cone related
Table 2 Effects of drusen on electrophysiological indices of visual function

\begin{tabular}{|c|c|c|c|}
\hline \multicolumn{3}{|c|}{ Total root mean square signal size } & \multirow[b]{2}{*}{$\begin{array}{l}t \text { test } \\
p\end{array}$} \\
\hline $\begin{array}{l}\text { Field } \\
\text { size }\end{array}$ & $>10$ drusen & $<=10$ drusen & \\
\hline $\begin{array}{l}30^{\circ} \\
15^{\circ}\end{array}$ & $\begin{array}{l}\text { Retina } \\
3822(745)(n=7) \\
1433(666)(n=6) \\
\text { Cortex }\end{array}$ & $\begin{array}{l}\text { Retina } \\
6220(2712)(\mathrm{n}=8) \\
2337(703)(\mathrm{n}=7) \\
\text { Cortex }\end{array}$ & $\begin{array}{l}0.044 \\
0.064\end{array}$ \\
\hline $\begin{array}{l}30^{\circ} \\
15^{\circ}\end{array}$ & $\begin{array}{r}1675(264)(n=7) \\
945(302)(n=6)\end{array}$ & $\begin{array}{l}1553(703)(n=8) \\
1154(842)(n=7)\end{array}$ & $\begin{array}{l}0.968 \\
0.576\end{array}$ \\
\hline
\end{tabular}

electroretinograms (ERGs) in affected animals. Bellhorn et $a l^{26}$ found no drusen associated degradation in signals from the eyes or cortices of US animals, with conventional, cone selective, and patterned stimuli. Thus, while loss of retinal resolution capacity is associated with drusen in our small sample of tested CPRC monkeys, the nature of this relationship and of differences between CPRC and mainland monkeys are unresolved.

A question raised - explicitly or implicitly - in several macaque AMD studies involves the relative paucity of neovascular lesions in monkeys. ${ }^{1026}$ Stafford et al identified seven eyes in four animals among their 574 elderly monkeys (mostly rhesus) having probable choroidal neovascular lesions. ${ }^{4}$ These animals were 8-15 dioptres myopic. ${ }^{14}$ Myopia has been linked to macular lesions, as these authors note, ${ }^{14}$ while AMD correlates with hyperopia in humans. ${ }^{21-23}$ We have reported one monkey with a disciform macular lesion ophthalmoscopically identical to those seen in human AMD ${ }^{8}$ The prevalence of severe macular serous and exudative lesions in the Framingham Eye Study was $0.78 \%$ (29 of 5253). ${ }^{18}$ This compares favourably with $0.7 \%$ of Stafford and coworkers, ${ }^{14}$ monkeys and $0.4 \%$ of our sample. These lesions therefore appear to have been encountered in monkeys at about the same relative frequency as reported in humans. The infrequent observation of end-stage or neovascular lesions in monkeys is probably a function of the relatively few very old monkeys examined.

El-Mofty $e t a l^{10}$ found that $25 \%$ of the nonselected CPRC monkeys they examined had drusen, which is consistent with our observations on several matrilines (note Fig 4a-b). Comparison of CPRC monkeys with random source monkeys from US mainland facilities is more interesting. Bellhorn $e t a l^{26}$ and Stafford $e t$ $a l^{14}$ studied relatively large samples $(\mathrm{n}=500-600)$ and found that only about $6 \%$ showed druse-like lesions. If all category 1 (1-5 drusen) CPRC animals are eliminated, comparison with Stafford and coworkers' ${ }^{1+}$ older monkeys having five or more drusen indicates that $21 \%$ of the CPRC monkeys are affected, compared with $6 \%$ of their sample of US animals. Bellhorn and coworkers $^{26}$ minimum criterion ( $<10$ drusen) appears to indicate that some $6 \cdot 1 \%$ of their animals had drusen, compared with $57 \cdot 7 \%$ of the CPRC monkeys. Apparently, therefore, the prevalence of monkeys with lesions in the CPRC colony is up to nine times that of monkeys on the US mainland.

CPRC animals differ from those in US facilities in many respects. The CPRC animals are 
mostly free ranging and are geophagous. ${ }^{30}$ They thus may differ from monkeys in US facilities in content of, and/or access to, soil. Several elements have been found to occur in abnormal concentrations in the blood and, notably, drusen of AMD patients. ${ }^{31-34}$ CPRC animals are also subjected to lifelong exposure to more direct Caribbean sunlight. A solar irradiation contribution to human AMD, while generally suspected, has been unsupported or supported only indirectly. ${ }^{35-37}$ However, recently presented epidemiological evidence implicates exposure to the blue portion of the visible spectrum late in life as a possible risk factor in AMD.$^{38}$ Influences due to differences in ingested minerals and elements and differential solar irradiation offer interesting, though speculative possibilities for exploration.

Finally, since no animals have been added to the colony since $1938,{ }^{16}$ all current inhabitants of the island are the progeny of the breeding females surviving the original introduction. While males tend to migrate among social groups, females tend to remain in the group into which they are born..$^{39}$ Early introduction of a genetic propensity to develop drusen could, in the succeeding eight to 10 generations, have been transmitted through the closed colony by males yet be more heavily represented in a few primarily affected matrilines. Relationships between maternal lineage and drusen development demonstrated here and the familial - especially maternal - associations observed in AMD in humans $\mathrm{s}^{22}$ implicate this as a potentially important factor in explaining the dramatic difference between drusen prevalence in CPRC monkeys and their US counterparts.

The evidence indicates that all features associated with age related macular drusen in humans can be found in the CPRC rhesus population. Comparisons of these monkeys with those from other populations suggest that this colony is uniquely predisposed to develop drusen. While environmental factors may have a role, the associations between drusen development and matriline shown above suggest that a major difference between this closed colony and others surveyed is probably genetic, hence their uniqueness. It appears therefore that CPRC matriline monkeys offer the best human substitute reported so far for the study of spontaneous development of age related drusen, the principal precursor to age related macular degeneration.

This work was supported by NIH Grant 1 P40 RR3640 to the Carribbean Primate Research Center; NEI Grant 2R01 EY04460 to W W Dawson; and an unrestricted grant from Research to Prevent Blindness to the Department of Ophthalmology, University of Florida.

1 Bressler NM, Bressler SB, Fine SL. Age-related macular degeneration. Surv Ophthalmol 1988; 32: 375-413.

2 Ferris FL III. Senile macular degeneration: review of epidemiologic features. $A m \mathcal{F}$ Epidemiol 1983; 118: 132-51.

3 Gass JDM. Stereoscopic atlas of macular diseases, diagnosis and treatment. 2nd ed. St Louis: Mosby, 1977.

4 Tso MOM. Pathogenic factors of aging macular degeneration. Ophthalmology 1985; 92: 628-35.

5 Ishibashi T, Patterson R, Ohnishi Y, Inomata H, Ryan S Formation of drusen in the human eye. Am $\mathcal{F}$ Ophthalmo 986; 101: 342-53.

6 Ulshafer RJ, Engel HM, Dawson WW, Allen CB, Kessler MJ Macular degeneration in a community of rhesus monkeys. Retina 1987; 7: 198-203.
7 Dawson WW, Ulshafer RJ, Engel HM, Hope GM, Kessler MJ. Macular disease in related rhesus monkeys. Doc Ophthalmol 1989; 71: 253-64.

8 Dawson WW, Engel HM, Hope GM, Kessler MJ, Ulshafer RJ. Age onset macular degeneration. Puerto Rico Health Scif 1989; 8: 111-5.

9 El-Mofty AAM, Gouras P, Eisner G, Balaz EA. Macular degeneration in rhesus monkey Macaca mulatta. Exp Eye Res 1978; 27: 499-502.

10 El-Mofty AAM, Eisner G, Balaz EA, Denlinger JL, Gouras P. Retinal degeneration in rhesus monkeys Macaca mulatta. Retinal degeneration in rhesus monkeys Macaca mulatta. Survey of three seminatur

11 Engel HM, Dawson WW, Ulshafer RJ, Hines MW, Kessler MJ. Degenerative changes in maculas of rhesus monkeys. Ophthalmologica 1988; 196: 143-50.

12 Fine BS, Kwapien RP. Pigment epithelial windows, drusen: animal model. Invest Ophthalmol Vis Sci 1978; 17: 1059-68.

13 Stafford TJ. Maculopathy in an elderly sub-human primate. Mod Probl Ophthalmol 1974; 12: 214-9.

14 Stafford TJ, Anness SH, Fine BS. Spontaneous degenerative maculopathy in the monkey. Ophthalmology 1984; 91: 513-21.

15 Ishibashi T, Sorgente N, Patterson R, Ryan S. Pathogenesis of drusen in the primate. Invest Ophthalmol Vis Sci 1986; 27: 184-93.

16 Rawlins RG, Kessler MJ. (1986) The history of the Cayo Santiago colony. In: Rawlins RG, Kessler MJ, eds. The Cayo Santiago Macaques. Albany: State University of New York Press, 1986: 13-45.

17 Dawson WW, Maida TW. Relations between the human retinal cone and ganglion cell distribution. Ophthalmologica 1984; 188: 216-21.

18 Leibowitz H, Krueger D, Maunder L, Milton R, Kini M, Kahn $\mathrm{H}$, et al. The Framingham eye study monograph. Surv Ophthalmol 1980; 24 (suppl): 335-610.

19 Kessler M, Berard J. A brief description of the Cayo Santiago rhesus monkey colony. Puerto Rico Health Sci f 1989; 8: 55-9.

20 Ordy JM, Brizzee KR. Visual acuity and foveal cone density in the retina of the aged rhesus monkey. Neurobiol Aging 1980; 1: $133-40$.

21 Delaney WV Jr, Oates RP. Senile macular degeneration: a preliminary study Ann Ophthalmol 1982;14:21-4.

22 Hymen LG, Lilienfeld AM, Ferris FL III, Fine SL. Senile macular degeneration: a case-control study. Am $\mathcal{F}$ Ep pidemiol 1983; 118: 213-27.

23 Maltzman BA, Mulvihill MN, Greenbaum A. Senile macular degeneration and risk factors: a case-control study. Ann Ophthalmol 1979; 14: 1197-201.

24 Ulshafer RJ, Allen CB, Nicolaissen D, Rubin ML. Scanning electron microscopy of human drusen. Invest Ophthalmol Vis Sci 1987; 28: 683-9.

25 Feeney-Burns L, Malinow MR, Klein ML, Neuringer $M$. Maculopathy in cynomolgus monkeys. A correlated fluorescein angiographic and ultrastructural study. Arch Ophthalmol 1981; 99: 664-72.

26 Bellhorn RW, King CD, Aguirre GD, Ripps H, Siegel IM, Tsai HC. Pigmentary abnormalities of the macula in rhesus monkeys: clinical observations. Invest Ophthalmol Vis Sci monkeys: clinical

27 Odum J, Dawson W, Maida T. Human pattern-evoked retinal and cortical potentials. II. The second international evoked potentials symposium. Boston: Butterworths, 1984: 536-42.

28 Odum J, Bromberg N, Dawson W. Canine visual acuity: retinal and cortical field potentials evoked by pattern stimulation. Am f P hysiol 1983; 245: 637-41.

29 Dawson WW, Stratton RD, Hope GM, Parmer R, Engel HM, Kessler MJ. Tissue responses of the monkey retina: tuning and dependence on inner layer integrity. Invest Ophthalmol Vis Sci 1986; 27: 734-45.

30 Marriott BM, Roemer J, Sultana C. An overview of food intake patterns of the Cayo Santiago rhesus monkeys (Macaca mulatta): report of a pilot study. Puerto Rico Health $S c i \mathcal{F}$ 1989; 8: 87-94.

31 Ulshafer RJ, Allen CB, Rubin ML. Distribution of elements in human retinal pigment epithelium. Arch Ophthalmol (in press).

32 Ulshafer RJ. Zinc content in melanosomes of degenerating RPE as measured by $x$ ray mapping. In: LaVail $M$, Anderson RE, Hollyfield JG, eds. Inherited and environmentally induced retinal degenerations. New York: Liss, 1989: 131-9.

33 Miller ED, Schwartz M, Leone NC, Bennecoff TA, Newsome DA. Serum zinc concentration in macular degeneration. Invest Ophthalmol Vis Sci 1986; 27 (suppl): 20

34 Newsome DA, Schwartz M, Leone NC, Elston RC, Miller ED. Oral zinc in macular degeneration. Arch Ophthalmol 1988; 106: 192-8.

35 Liu IY, White L, LaCroix AZ. The association of age-related macular degeneration and lens opacities in the aged. $A m \mathcal{F}$ Public Health 1989; 79: 765-9.

36 West SK, Rosenthal FS, Bressler NM, Bressler SB, Munoz B Fine SL, et al. Exposure to sunlight and other risk factors for Fine SL, et al. Exposure to sunlight and other risk factors for 107: 875-9.

37 Young RW. Solar radiation and age-related macular degeneration. Surv Ophthalmol 1988; 32: 252-69.

38 Muñoz B, West S, Bressler N, Bressler S, Rosenthal FS, Taylor HR. Blue light and risk of age-related macular degeneration. Invest Ophthalmol Vis Sci 1990; 31 (suppl): 49

39 Berard J. Life histories of male Cayo Santiago macaques. Puerto Rico Health Sci 1989; 8: 61-4. 